\title{
Correlated levels of mRNA and soma size in single identified neurons: evidence for compartment-specific regulation of gene expression
}

\author{
Joseph L. Ransdell, Tyler B. Faust and David J. Schulz* \\ Department of Biological Sciences, University of Missouri Columbia, Columbia, MO, USA
}

Edited by:

Bernard Attali, Tel Aviv University, Israel

Reviewed by:

Bernard Attali, Tel Aviv University, Israel

Edward C. Cooper, Baylor College of

Medicine, USA

*Correspondence:

David J. Schulz, Department of

Biological Sciences, University of

Missouri, Columbia, MO, 65211, USA.

e-mail: schulzd@missouri.edu
In addition to the overall complexity of transcriptional regulation, cells also must take into account the subcellular distribution of these gene products. This is particularly challenging for morphologically complex cells such as neurons. Yet the interaction between cellular morphology and gene expression is poorly understood. Here we provide some of the first evidence for a relationship between neuronal compartment size and maintenance of $m R N A$ levels in neurons. We find that single-cell transcript levels of 18S rRNA, GAPDH, and EF1-alpha, all gene products with primary functions in the cell soma, are strongly correlated to soma size in multiple distinct neuronal types. Levels of mRNA for the $\mathrm{K}^{+}$channel shal, which is localized exclusively to the soma, are negatively correlated with soma size, suggesting that gene expression does not simply track positively with compartment size. Conversely, levels of beta-actin and beta-tubulin mRNA, which are major cytoskeletal proteins of neuronal processes, do not correlate with soma size, but are strongly correlated with one another. Additionally, actin/tubulin expression levels correlate with voltage-gated ion channels that are uniquely localized to axons. These results suggest that steady-state transcript levels are differentially regulated based on the subcellular compartment within which a given gene product primarily acts.

Keywords: gene expression, mRNA levels, single-cell PCR, compartmentalization

\section{INTRODUCTION}

Coordination and regulation of gene expression is a common feature of cells across all organisms. This challenge is even more pronounced in cells with complex morphology such as neurons. Neurons must balance differing needs of distinct subcellular compartments, such as axons, dendrites, or even subsets of synapses that can be located over a meter from the soma. Yet it is not clear whether distinct compartmental needs are served largely by localized mechanisms of mRNA and protein trafficking (Bramham and Wells, 2007; Tubing et al., 2010), local translational regulation (Martin et al., 2000; Ashraf et al., 2006), or whether there is feedback in a compartment-specific nature on transcription itself. Transcriptional events mediated by retrograde signaling are invoked and necessary for axonal growth and regeneration (Smith and Pate Skene, 1997; Michaelevski et al., 2010), and indeed peripheral nerve lesion can lead to a large scale activation of phosphoproteins and transcriptional changes (Michaelevski et al., 2010) involved in retrograde injury signaling. These studies reveal a relationship between subcellular compartments and transcription. However, little is known about to what extent compartment-specific gene expression is controlled in different cell types.

Subcellular, compartment-specific transcriptional control has been known for some time in prokaryotes (Rather and Moran, 1988), but our understanding of this phenomenon in eukaryotic cells is relatively poor. To shed light on this question requires a system where transcription levels for gene products with distinct compartmental localization can be measured at the level of single cells. To begin to determine whether compartment-specific mechanisms of transcriptional control may exist in eukaryotic cells, we used neurons of two central pattern generator circuits (the pyloric and gastric) found in the stomatogastric ganglion (STG) of the crab, Cancer borealis. The STG contains 26-27 neurons of at least 14 different types (Kilman and Marder, 1996) that all can be individually identified on the basis of anatomical projections (Maynard and Dando, 1974). The cellular morphology can be revealed by dye injection and imaging (Bucher et al., 2007; Thuma et al., 2009), and the cells can be individually harvested for molecular analysis, thus making the STG an ideal system to determine cell-specific patterns of gene expression (Schulz et al., 2006, 2007). In this study we use six different cell types, five that belong to the pyloric network, and one that belongs to the gastric circuit.

In these cells, we quantified transcript levels for multiple classes of proteins with distinct subcellular localization (Table 1). We chose three transcripts with functions that occur predominantly, but not exclusively, in the soma of the cell: the 18S rRNA subunit, elongation factor 1-alpha (EF1-alpha), and glyceraldehyde-3-phosphate dehydrogenase $(G A P D H)$. While RNA for all three of these genes has been localized to axons or dendrites (Yuan et al., 1999; Giustetto et al., 2003; Giuditta et al., 2008), the overwhelming predominance of these gene products, as revealed by immunofluorescence, is in the soma (Bluem et al., 2007; Tubing et al., 2010). We also chose genes for two cytoskeletal elements with ubiquitous distribution, beta-actin and beta-tubulin. These products have been localized throughout the soma and neurites (Spooner and Holladay, 1981; Goldman, 1983). STG neurons have finely branched neuritic processes with a combined total length of approximately $3-4 \mathrm{~mm}$ 
Table 1 | Gene products used in this study.

\begin{tabular}{|c|c|c|c|}
\hline Gene product & Gene name & Primary function & Primary locale \\
\hline $18 \mathrm{~S}$ rRNA & $18 S$ & Translation, small ribosomal subunit & Soma \\
\hline Elongation factor 1-alpha & EF1-alpha & Translation, delivery of aminoacyl tRNA to the ribosome & Soma \\
\hline $\begin{array}{l}\text { Glyceraldehyde 3-phosphate } \\
\text { dehydrogenase }\end{array}$ & GAPDH & Glycolysis, catalyzes conversion of glyceraldehyde 3-phosphate & Soma \\
\hline Beta-actin & beta-actin & $\begin{array}{l}\text { Cytoskeleton, monomeric subunits of microfilaments, } \\
\text { internal cell motility }\end{array}$ & Ubiquitous \\
\hline Beta-tubulin & beta-tubulin & Cytoskeleton, subunit of microtubules & Ubiquitous \\
\hline Shaker & shaker & Voltage-gated $\mathrm{K}^{+}$channel alpha subunit, A-type current (Kv1) & Axon \\
\hline Shaker cognate $L$ & shal & Voltage-gated K+ channel alpha subunit, A-type current (Kv4) & Soma \\
\hline Voltage-dependent $\mathrm{Na}^{+}$channel & $\mathrm{CbNa}$ & Voltage-gated $\mathrm{Na}^{+}$channel alpha subunit, fast sodium current & Axon \\
\hline
\end{tabular}

(Bucher et al., 2007; Thuma et al., 2009). However, their axons project up to 4-6 cm (Maynard and Dando, 1974). It is reasonable to hypothesize that the overwhelming abundance of actin and tubulin is therefore likely within the axons of STG neurons. Finally, we chose three voltage-gated ion channels with distinct subcellular localization in the STG. Using immunofluorescence, shal has been localized to the soma (Baro et al., 2000), while shaker has been localized to the axon (Baro et al., 2000). In addition, the voltagegated sodium current, for which there is only one known channel gene $\left(\mathrm{CbNa} \mathrm{v}_{v}\right)$, has been localized to the axon via electrophysiological measurements (Graubard and Hartline, 1991; Golowasch and Marder, 1992).

Our overall logic and experimental design were as follows. We first investigated whether genes of fundamental cellular functions such as 18s rRNA, EF1-alpha, GAPDH, actin, and tubulin were regulated in such a way that steady-state mRNA levels scale with cell soma size. When we discovered that mRNA levels of only three of these genes (18S, EF1-alpha, and GAPDH) were correlated with soma size, while actin and tubulin were not, we hypothesized that perhaps gene expression is regulated according to which subcellular compartment each gene product predominantly was most abundant. To investigate whether mRNA levels are maintained in this compartment-specific manner, we quantified RNA copies from single identified cells for voltage-gated ion channels that can be localized to one of two compartments: the cell body/soma, or the axon. Our hypothesis is that if mRNA levels are maintained in a compartment-specific manner, then levels of RNA for a given transcript should be correlated to the size of that compartment in a given neuron type. We tested this hypothesis further by determining whether mRNA levels for ion channels of known localization correlate with size of either the soma or the abundance RNA for cytoskeletal elements (actin and tubulin) likely to be in greatest abundance in the axon.

\section{MATERIALS AND METHODS ANIMALS}

Live $C$. borealis crabs were shipped overnight from The Fresh Lobster Company (Gloucester, MA, USA) and kept in artificial sea water at $12^{\circ} \mathrm{C}$ until used. Crabs were anesthetized on ice for $15 \mathrm{~min}$ before dissection. The stomatogastric nervous system was dissected out of the crab stomach and pinned on a sylgard coated dish (Dow Corning). The entirety of the dissection took place in physiological saline comprised of $440 \mathrm{mM} \mathrm{NaCl}, 11 \mathrm{mM} \mathrm{KCl}$,
$13 \mathrm{mM} \mathrm{CaCl}_{2}, 26 \mathrm{mM} \mathrm{MgCl}, 11.2 \mathrm{mM}$ Trizma base and $5 \mathrm{mM}$ Maleic acid ( $\mathrm{pH}=7.4)$. All experiments were performed in accordance with institutional and national guidelines and regulations.

\section{ELECTROPHYSIOLOGY}

For electrophysiological recordings, the STG was desheathed, and petroleum jelly wells were placed on the motor nerves. Extracellular recordings from the nerves were made by placing stainless steel pin electrodes in the wells. Signals were amplified and filtered using a model 1700 differential AC amplifier (A-M Systems, Sequim, WA, USA). Intracellular recordings from STG somata were made using 15-20 M $\Omega$ glass microelectrodes filled with $3 \mathrm{M} \mathrm{KCl}$ and an Axoclamp 2A amplifier (Axon Instruments, Sunnyvale, CA, USA). During recordings, the preparations were maintained with chilled $\left(12-13^{\circ} \mathrm{C}\right)$ physiological saline. Unless otherwise specified, chemicals were obtained from Fisher Chemical (Fairlawn, NJ, USA). Data were acquired using a Digidata 1322 data acquisition board (Axon Instruments).

\section{MEASURING SOMA AREA}

Cell soma morphology of identified neurons was revealed by iontophoretic injection of AlexaFluor 568 hydrazide (sodium salt, $10 \mathrm{mM}$ in $200 \mathrm{mM} \mathrm{KCl}$; Invitrogen, Carlsbad, CA, USA). The cells were identified with standard procedures for C. borealis (Hooper et al., 1986; Weimann et al., 1991). We targeted six different neuron types of the STG: LG (lateral gastric), LP (lateral pyloric), PD (pyloric dilator), IC (inferior cardiac), LPG (lateral pyloric gastric), and PY (pyloric). Upon successful identification of a target neuron the cell soma was filled iontophoretically by overriding the capacitance of the intracellular electrode. Several cells were often filled in the same animal but cells within close proximity of one another were never filled together; this prevented error in overlapping fluorescence measurements.

Following dye fills, the STG was dissected out of the STNS with small pieces of surrounding nerves still attached. The STG was then pinned on a thin piece of Sylgard (Dow Corning, Midland, MI, USA), inverted and placed on a microscope slide in physiological saline. Preparations remained un-fixed to avoid any change in soma volume as a result of fixation or dehydration. $10 \times$ fluorescent images of the STG were taken with an Olympus IX70 microscope and ORCA-AG camera at the University of Missouri-Columbia Cytology Core (Figure 1B). These images were analyzed with 
A

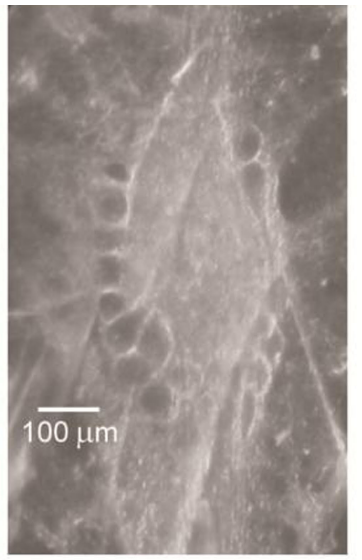

B

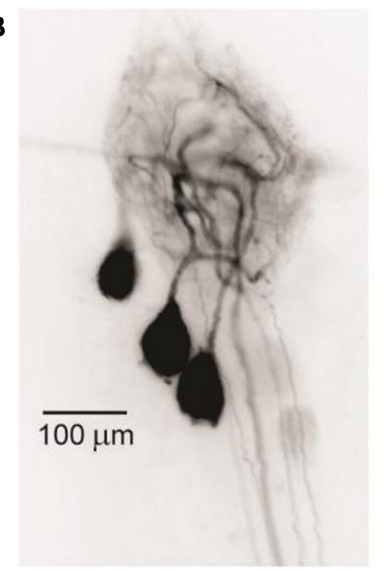

C

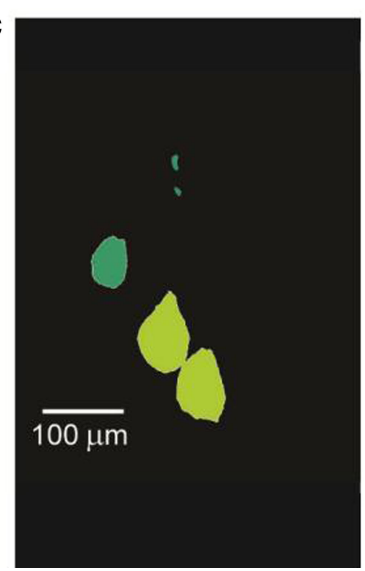

FIGURE 1 | Representative images demonstrating the measurements of soma size in STG neurons. (A)The STG consists of cell somata surrounding an area of central neuropil. (B) Individual neurons can be identified, and their somata filled with dye. (C) Following dye fill, the somata areas are digitized and quantified with Metamorph software. (B,C) From the same animal, $(\mathbf{A})$ is a different individual. Scale bars as indicated.

Metamorph software (Molecular Devices, Sunnyvale, CA, USA). The image was calibrated to a $10 \times$ objective and the somata were isolated from the neurite using a threshold algorithm (Figure 1C). Area measures of the isolated cell soma were taken and normalized to a PD cell's soma area within the same preparation to avoid any variability due to mounting conditions and/or focal length. The total time elapsed from dye fill to imaging of the soma was between 1 and $2 \mathrm{~h}$. Area measurements have been shown to correlate with cell volume across multiple species (Satoh et. al., 1996). Figure 1 displays an example of cell soma measurements in a single STG.

\section{CLONING OF GAPDH, EF1-ALPHA, ACTIN, AND TUBULIN FROM CANCER BOREALIS}

We cloned and sequenced four new open reading frames (ORFs) from the crab, C. borealis, for use in quantitative PCR assays, including glyceraldehyde-3-phosphate dehydrogenase (GAPDH), elongation factor 1-alpha (EF1A), beta-tubulin, and beta-actin. GenBank accession numbers for the sequences are as follows $(C b=C$. borealis): Cb-GAPDH HM157285, Cb-EF1-alpha HM157286, Cb-betaactin HM157287, Cb-beta-tubulin HM157288. All amino acid sequences reported and discussed in this study are predicted amino acid sequences based on cDNA sequence.

Because there is a paucity of sequence information available for $C$. borealis, we employed degenerate PCR to identify ORFs for these genes. Total RNA was isolated from mixed crab brain and heart tissue with Trizol (Invitrogen, Carlsbad, CA, USA). Partial ORFs were amplified separately by RT-PCR from a common pool of cDNA generated by oligo-dT primed total RNA that was reverse transcribed using SuperScript III reverse transcriptase (Invitrogen) and amplified with GoTaq DNA polymerase (Promega, Madison, WI, USA). PCR products were cloned into pGEM-Teasy vector (Promega) and their identities confirmed by sequencing (DNA Core, University of Missouri, Columbia, MO, USA), with subsequent sequence comparison to other species via the BLASTX and BLASTN algorithms (NCBI, Bethesda, MD, USA).

\section{QUANTIFYING SINGLE CELL GENE EXPRESSION}

The somata of individually identified neurons of the STG were harvested as described in detail elsewhere (Schulz et al., 2006). Briefly, the cells were identified as described above and then the cells were partially dissociated enzymatically (Collagenase Type I, SigmaAldrich, St. Louis, MO, USA). The physiological saline was replaced with $70 \%$ ethylene glycol, and frozen at $-80^{\circ} \mathrm{C}$ for $1 \mathrm{~h}$. Individual cell somata then were harvested by hand-held forceps while still cold, and placed into $350 \mu$ lysis buffer (buffer RLT as provided by Qiagen, Valencia, CA, USA) containing $1 \% \beta$-mercaptoethanol and frozen at $-80^{\circ} \mathrm{C}$ until RNA extraction. For all RNA quantification data, we use only the soma of the neuron, as we cannot collect a consistent portion of the neurites of these cells across animals.

Quantitative PCR was performed as previously described (Schulz et al., 2006). Briefly, total RNA was isolated using RNeasy micro column based RNA extraction kit (Qiagen, Valencia, CA, USA), reverse transcribed using SuperScript III reverse transcriptase (Invitrogen), and used as a template in real-time RT-PCR with Sybr Green (SABiosciences, Frederick, MA, USA). Primers specific for realtime PCR detection of ion channels shal, shaker, $\mathrm{CbNa}$, and $18 \mathrm{~S}$ rRNA using Sybr Green were developed and designed using Primer3 software and are the same as previously reported (Schulz et al., 2006, 2007; Tobin et al., 2009). New primers also were generated for the quantification of GAPDH, EF1-alpha, beta-actin, and betatubulin as follows: GAPDH-F5'-CCTTTCATTGCCCTGGACTA-3'; GA P D H - R 5' - CATCA A C A A C CA GA GC TC C A - 3'; EF 1 - alpha-F5' - GGCCTCAGACTCAAAGAACG-3'; EF1-alpha-R5' - AGTAGCCAGCCTGGATCTGA-3'; beta-actin- $5^{\prime}$ - TCGAAACCT TCAACACTCCC-3'; beta-actin-R5'-ACCGGAGTCGAGCACAATAC-3'; beta-tubulinF5'-TCAGCTGACACACTCCCTTG-3'; beta-tubulin-R 5'-CGGCACAACAGAGAAAGTGA-3'.

\section{STATISTICS}

Differences among cell types for a given measurement (cell size or gene expression) were analyzed with a one-way ANOVA with post hoc Tukey's $t$-tests. Relationships among variables were 
analyzed using Pearson's correlation. All statistical tests were performed using SigmaPlot v11.0 (Systat Software, Inc. San Jose, CA, USA).

\section{RESULTS \\ CLONING OF cDNA FOR GAPDH, EF1-ALPHA, BETA-ACTIN, AND BETA-TUBULIN FROM CANCER BOREALIS}

In this study we generated 1005 bp of sequence information to obtain full length $G A P D H, 1386$ bp of sequence to obtain full length EF1alpha, 520 bp to obtain partial beta-actin, and 586 bp of sequence to obtain partial beta-tubulin, which represents approximately 49 and $43 \%$ of the total actin and tubulin sequences respectively. Our sequences share $78 \%$ amino acid identity to the Drosophila melanogaster GAPDH gene (Accession Number ABH06723), $79 \%$ amino acid identity to the D. melanogaster EF1-alpha gene (Accession Number AAF57185), 97\% amino acid identity to the $D$. melanogaster actin gene (Accession Number AAF46098), and 91\% identity to the D. melanogaster tubulin gene (Accession Number AAF57556).

\section{SOMA AREA MEASUREMENTS AMONG IDENTIFIED NEURONS OF THE STG}

To ensure that measurements of soma area were not affected by differences in mounting of the preparation, the neuronal soma area of each identified cell was normalized to a PD cell soma area within that ganglion. This soma size is expressed as a relative measure with PD values set to 1.0. Measured in this way the STG cells showed significant differences in their somata areas among cell types $(p<0.001$, ANOVA). Mean cell somata sizes ranked from largest to smallest as follows: $\mathrm{LG}>\mathrm{LP}>\mathrm{PD}>\mathrm{IC}>\mathrm{LPG}>\mathrm{PY}$ (Figure 2A). LG neurons were consistently the largest neuron in a given ganglion, with a mean size approximately $135 \%$ of that of PD. Conversely, PY cells were consistently the smallest in a given ganglion, measuring approximately $60 \%$ the size of PD cells and less than half the size of LG.

\section{SINGLE-CELL GENE EXPRESSION MEASUREMENTS FROM THE SOMATA OF IDENTIFIED NEURONS OF THE STG}

To examine the relationship between gene expression and cell architecture, we quantified mRNA levels of eight different genes from six different classes of single identified neurons of the STG. A summary of these genes and their gene products is provided in Table 1.

mRNA levels of the five different genes associated with fundamental processes found in all cells varied significantly among cell types (Figure 2), including $18 \mathrm{~S}$ rRNA $(p<0.001), G A P D H$ $(p<0.001)$, EF1-alpha $(p<0.001)$, beta-actin $(p<0.008)$, and betatubulin $(p<0.005)$. However, the relative expression levels among cell types were not conserved among all of these genes. Furthermore, the expression levels of all gene products did not correlate with cell soma size. Levels of $18 \mathrm{~S}$ rRNA, GAPDH, and EF1-alpha followed a similar relative abundance of expression among cell types as to that for their relative soma sizes; i.e., LG > LP > PD > IC > LPG > PY, with the exception that IC $>$ PD for 18S rRNA (Figures 2B-D). Conversely, levels of actin and tubulin mRNA did not follow this pattern (Figures 2E,F).

\section{CORRELATIONS AMONG GENE EXPRESSION AND CELL SOMA SIZE IN SINGLE IDENTIFIED NEURONS}

To more thoroughly examine the relationships among gene expression and cell soma size, we performed correlation analyses. 18S rRNA expression and cell soma size were strongly correlated $\left(p<0.001 ; R^{2}=0.98\right.$; Figure 3A). EF1-alpha $\left(p<0.005 ; R^{2}=0.91\right.$; Figure 3B $)$ and $G A P D H\left(p<0.005 ; R^{2}=0.91\right.$; Figure 3C) also were significantly correlated with cell soma size. Conversely, there were only weak and not statistically significant relationships between cell soma size and expression of $\operatorname{actin}\left(p=0.08 ; R^{2}=0.57\right.$; Figure 3D), and tubulin ( $p=0.06 ; R^{2}=0.62$; Figure $\left.3 \mathrm{E}\right)$.

We further examined the relationships among the expression of these various genes, and found a particularly strong relationship between GAPDH and EF1-alpha $\left(p<0.001 ; R^{2}=0.98\right.$; Figure 4A) as well as significant correlations between both EF1alpha and GAPDH with $18 \mathrm{~S}$ rRNA $\left(p<0.005 ; R^{2}=0.91\right.$ for both; Figures 4B,C). Conversely, there were no significant relationships between actin and tubulin with any of these three genes (GAPDH, EF1-alpha, or $18 S$ rRNA). However, the strongest relationship between any two factors measured was a significant correlation between levels of actin and tubulin across cell types $(p<0.001$; $R^{2}=0.99$; Figure 4D).

Because there was a far weaker relationship between actin, tubulin, and soma size, we hypothesized that the complex architecture of neurons and their extensive processes (and thus cytoskeletal infrastructure) may require differences in mRNA levels for these gene products that are strongly related to their subcellular localization (i.e., soma vs. processes). To explore this hypothesis, we analyzed the mRNA levels of three different voltage-gated ion channels (Table 1), as the subcellular distribution of these channel proteins is documented. shal is a $\mathrm{K}^{+}$channel localized to the soma of pyloric neurons (Baro et al., 2000), shaker is a $\mathrm{K}^{+}$channel localized to the axon of pyloric cells (Baro et al., 2000), and $\mathrm{CbNa}$ is a $\mathrm{Na}^{+}$channel that is likely localized to the axons of STG neurons (Graubard and Hartline, 1991; Golowasch and Marder, 1992). Overall, there were no significant correlations between shal and soma size. However, after inspecting the data we saw a possible correlation for shal expression among pyloric neurons [all neuron types except LG in this study are pyloric] (see Figure 5A). Therefore, we performed a second analysis that included only the pyloric cells. When LG (the only non-pyloric neuron in this study) is omitted in the second analysis, levels of shal mRNA were significantly negatively correlated with cell soma size $\left(p<0.005 ; R^{2}=0.93\right.$; Figure 5A). The subcellular localization of shal channels has not been directly investigated in the LG cell (Baro et al., 2000), and therefore may not be localized to the soma as in the pyloric cells. In this second analysis, there was a weaker and not statistically significant relationship between expression of shal and actin ( $p=0.08$; $R^{2}=0.71$; Figure 5B) and tubulin ( $p=0.07 ; R^{2}=0.73$; Figure 5C). Conversely, levels of shaker and $\mathrm{CbNa}$, expression, both of which are localized to the axon, had the opposite relationships to soma size and actin/tubulin expression. Shaker and $\mathrm{CbNa}$ expression were not significantly correlated to soma size $\left(p=0.08 ; R^{2}=0.69\right.$ for both; Figures 5D,G), but both shaker and $\mathrm{CbNa}_{v}$ were strongly correlated with actin $\left(p<0.001 ; R^{2}>0.98\right.$; Figures 5E,H) and tubulin $\left(p<0.001 ; R^{2}>0.95\right.$; Figures 5F,I $)$. 


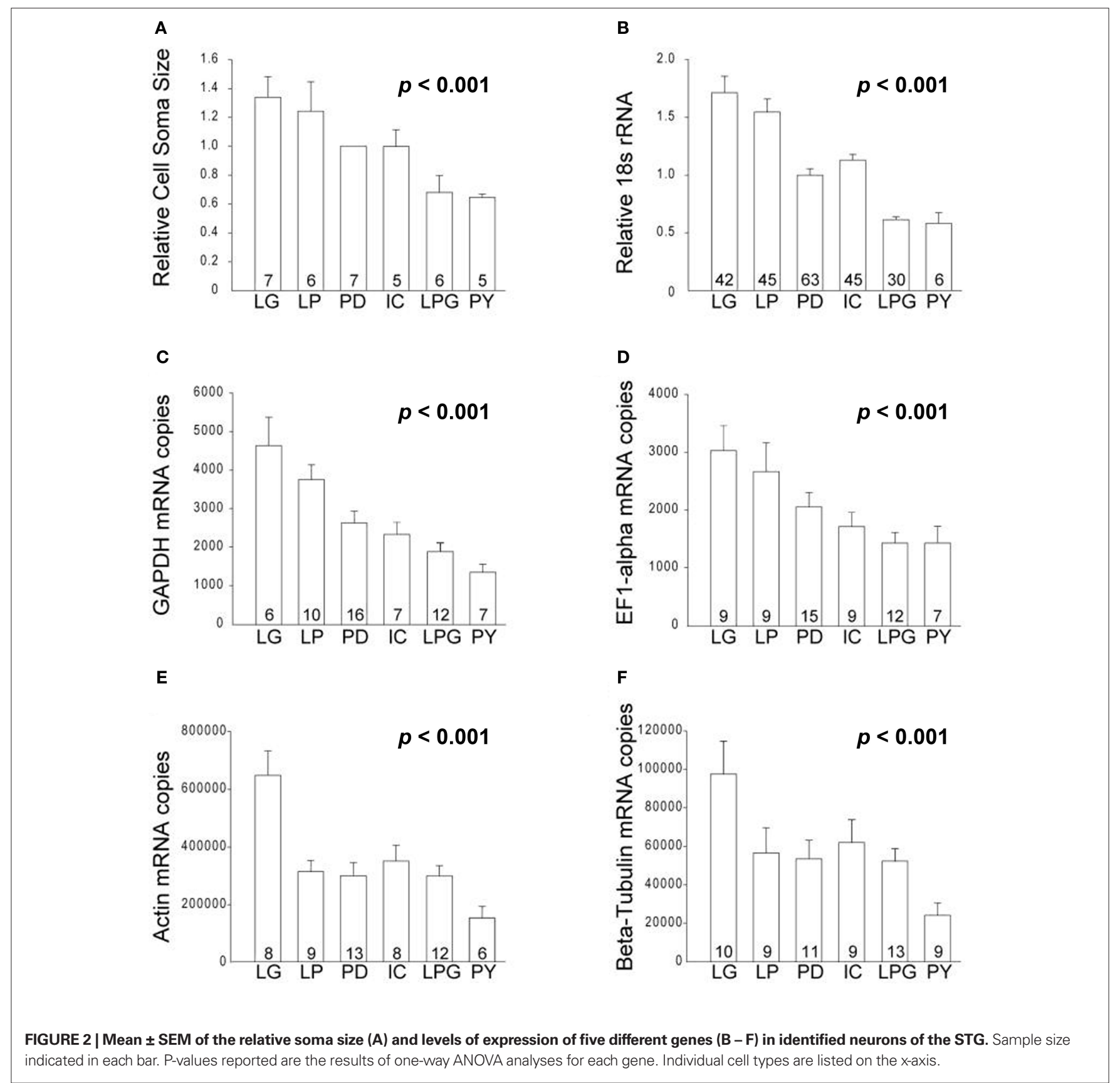

\section{DISCUSSION}

The highly compartmentalized nature of neurons presents a unique challenge for the cell in regulating gene expression for appropriate cellular function. Gene products must be regulated according to both the functional needs and morphological complexity of a given cell type. This study is one of the first to look at cell-specific patterns of gene expression in single identified neurons and correlate these expression patterns with morphological measurements of the neuron. Our results demonstrate that steady-state levels of 18S rRNA and mRNA for GAPDH, EF1-alpha, and the ion channel shal from single identified neurons are correlated with size of the soma of different neuron types. These gene products are known to be predominantly localized to the somatic compartments of these cells. Additionally, mRNA levels for actin, tubulin, and the axon-specific ion channels $\mathrm{CbNa}_{v}$ and shaker were strongly correlated with one another, but not soma size, across different cell types. These results provide some of the first evidence that in neurons steady-state mRNA levels are related in part to the size of a particular neuronal compartment, specifically the soma and perhaps the axon as well.

Our results also demonstrate that both soma area and levels of expression of multiple genes vary significantly across identified cell types of the STG. Differences in soma size also have been reported among the STG neurons from lobster, Panulirus 

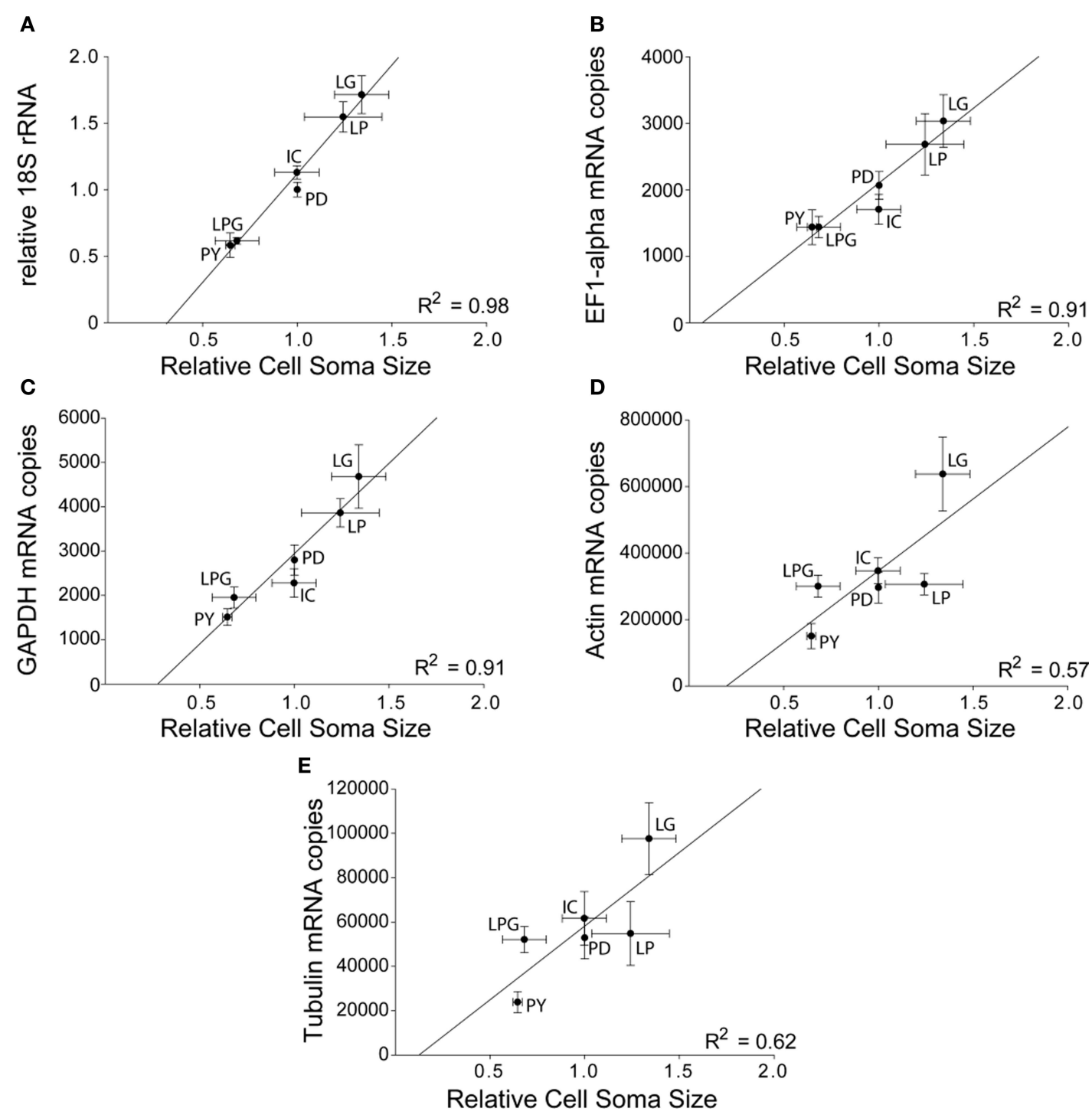

FIGURE 3 | Correlations between levels of gene expression ( $y$-axes) and cell soma size (x-axes) for five different genes (A - E). Points represent mean \pm SEM Individual neuron types as labeled, sample sizes listed in figure 1. Relative measurements are made with PD neurons as the reference population. R2 values are results of Pearson's correlation analyses.

interruptus (Thuma et al., 2009). The differences observed in lobster STG neurons are consistent with our measured differences. In both lobster and crab STGs, LP has one of the largest somata while PY has one of the smallest. We found robust correlations among cell soma size and gene expression for $18 \mathrm{~S}$ rRNA, EF1alpha, and GAPDH. These gene products are primarily involved in basal metabolic functions of cells. Therefore, our data suggest that there is a conserved regulation of cell size and metabolic function in cell types across species that is related to their common role in neural network output. Conversely, no significant differences have been reported in the maximum branch order and total neurite process length of STG cells (Thuma et al., 2009), nor is there a conserved morphology of neuritic processes of these cells (Bucher et al., 2007). However, the trends in these data indicate that the dendritic compartments of these cells do not simply scale with soma size, suggesting independent regulation of different neuronal compartments (Thuma et al., 2009). No functional significance has yet been determined for this variability in morphology.

It is also interesting to note that we observed both positive and negative correlations between soma size and gene products primarily localized to the soma. Levels of shal transcripts, a voltagegated $\mathrm{K}^{+}$channel localized to the soma (Baro et al., 2000), are negatively correlated to soma size (with the exception of the LG neuron). This negative correlation suggests that mRNA levels are actively regulated, positively and negatively, in a soma-specific manner, and is not simply an overall positive scaling with cell size. The negative relationship between shal and soma size provide the strongest evidence of a feedback relationship between compartment size (soma) and transcript numbers. The functional effect of this negative relationship is not yet known, but as shal encodes a 


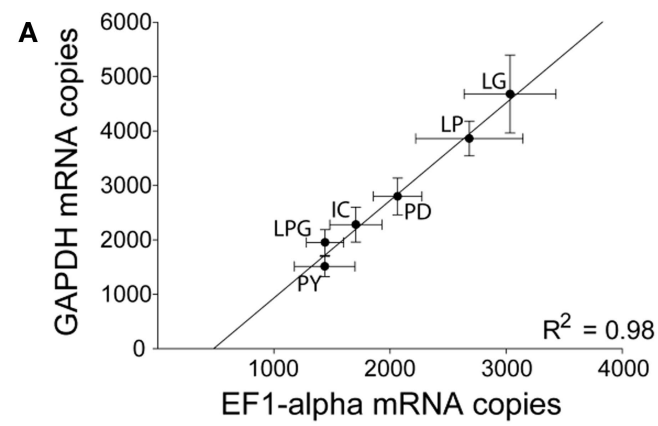

C

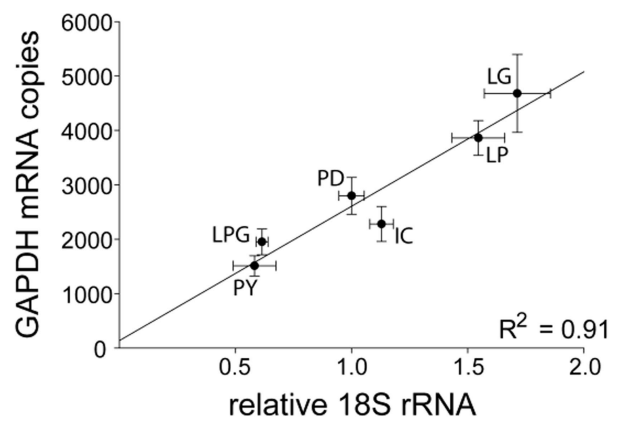

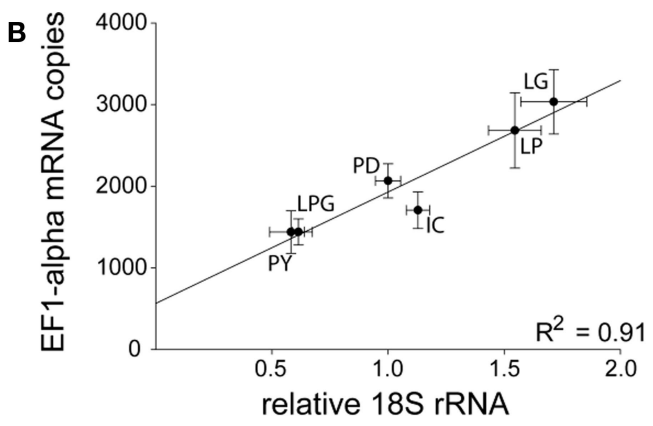

D

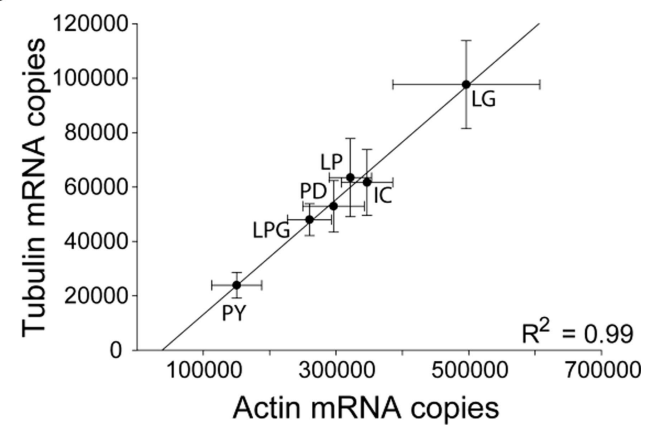

FIGURE 4 | Correlations among gene expression levels for different gene products. Points represent mean \pm SEM. Individual neuron types as labeled, sample sizes listed in Figure 1. Relative measurements are made with PD neurons as the reference population. $R^{2}$ values are results of Pearson's correlation analyses. (A-C) Pairwise correlations among 18S rRNA, EF1-alpha, and GAPDH. (D) Correlation between actin and tubulin expression levels.

voltage-gated $\mathrm{K}^{+}$current these results suggest a role for shal channels in regulating/maintaining the electrical properties of the cell soma compartment with respect to the functional output of the cell. Previous studies are consistent with the idea that changes in cell size are accommodated from an electrical point of view: as juvenile lobsters grow, the size of the STG neurons grow as well, but the overall electrical properties and outputs of the cell remain largely unchanged (Bucher et al., 2005). As these electrical properties are maintained throughout juvenile development and growth, it is likely compensation occurs via channel density to maintain these properties.

We were at first surprised to see that actin and tubulin did not correlate with soma size. However, because of the ubiquitous distribution of cytoskeletal proteins, and the fact that the majority of the cell volume is likely made up of the axon, we now hypothesize that abundance of actin and tubulin may act as an indirect assessment of size of the axonal compartment. Our data are consistent with this idea; actin and tubulin expression correlated very strongly with one another and with ion channels known to be localized to the axon, shaker, and $\mathrm{CbNa}_{v}$ (Golowasch and Marder, 1992; Baro et al., 2000). Such strong correlations among axon-specific products and cytoskeletal elements are consistent with, but not demonstrative of, a compartment-specific feedback influencing regulation of mRNA levels.

While our data demonstrate strong correlations between soma size and mRNA abundance, this correlation implies a rather simplistic relationship of compartment size and gene product with respect to distribution of the protein within the compartment itself. Specifically for this study, the shal channel does appear to be evenly distributed across the area of the somatic membrane (Baro et al., 2000). However, as the relationships revealed in this work are more specifically investigated at the protein level, we expect additional levels of complexity in this regulation to be revealed. For example, sub-compartment clustering of plasma membrane proteins, such as in the nodes of mammalian axons (Black et al., 1989), spike initiation zones of axon initial segments (Boiko et al., 2003) or signaling complexes of the membrane (Smith et al., 2006) will undoubtedly add further levels of regulatory processes. Indeed, further investigation will require a much more restrictive definition of what constitutes a "compartment" within a neuron. While the soma of a unipolar invertebrate neuron seems a relatively straightforward functional designation or unit, extending this logic to the coarse and fine neuropil (Bucher et al., 2007), axon collaterals, presynaptic terminals and post-synaptic signaling areas will present a far greater challenge in future work. Furthermore, channels and other proteins known to be localized to multiple compartmental regions (Caldwell et al., 2000) clearly must have other levels of regulation beyond mRNA abundance.

\section{CONCLUSIONS}

The highly compartmentalized nature of neurons results in the challenge of regulating functionality on a compartment-specific, rather than cell-wide, level. Although there is a great deal of evidence for localized regulation of protein trafficking and local translation in different subcellular compartments of neurons (Martin et al., 2000; Giustetto et al., 2003; Hobert, 2008), there has been little evidence 

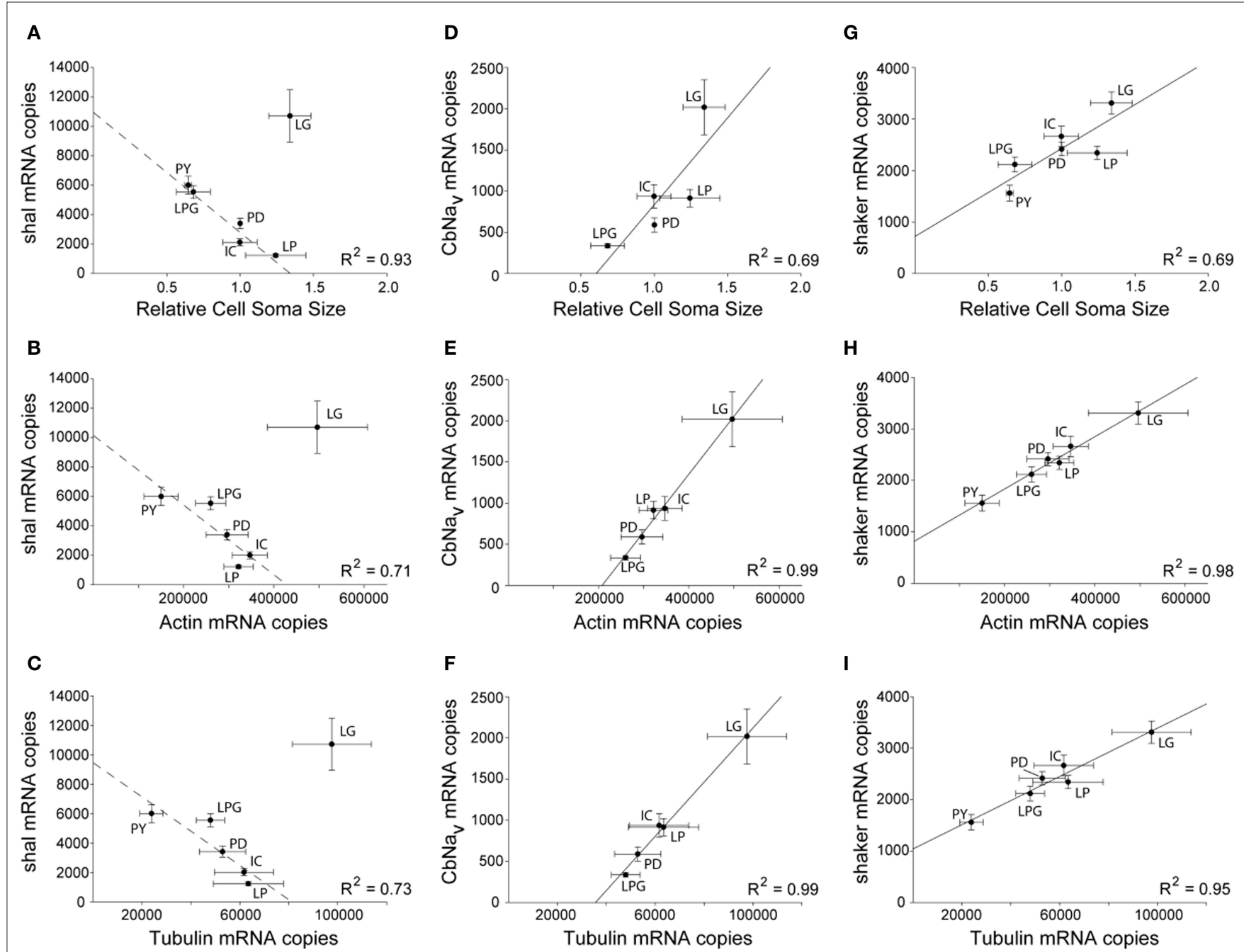

FIGURE 5 | Correlations between the voltage-gated ion channels shal (A-C), CbNa $(\mathrm{D}-\mathrm{F})$, and shaker (G-I) and soma size, actin, and tubulin expression. Points represent mean \pm SEM. Individual neuron types as labeled, sample sizes listed in Figure 1. Relative measurements are made with PD neurons as the reference population. Dashed lines represent regression fits for the second analysis that omits the LG neuron (see text). $R^{2}$ values are results of Pearson's correlation analyses.

up until this point that some of this regulation also occurs at the level of transcription and mRNA abundance. While our results suggest that mRNA levels are, in fact, influenced by feedback related to the soma size (and perhaps the axon), at this point the nature and mechanism of that feedback is unknown. This mechanism may involve retrograde signaling already implicated in injury signaling (Smith and Pate Skene, 1997; Michaelevski et al., 2010), or could represent distinct processes in mature, uninjured neurons. From the point of view of the soma, we also are left with two alternative hypotheses: namely, does cell soma size grow dynamically to

\section{REFERENCES}

Ashraf, S. I., McLoon, A. L., Sclarsic, S. M., and Kunes, S. (2006). Synaptic protein synthesis associated with memory is regulated by the RISC pathway in Drosophila. Cell 124, 191-205.
Baro, D.J., Ayali,A., French, L.,Scholz, N.L., Labenia, J., Lanning, C. C., Graubard, K., and Harris-Warrick, R. M. (2000). Molecular underpinnings of motor pattern generation: differential targeting of shal and shaker in the pyloric motor system. J. Neurosci. 20, 6619-6630. accommodate changes in metabolic needs of the rest of the cell, or is soma size developmentally determined, and then "filled" after the fact? Determining the answers to these questions will provide further important insight into the juggling act of transcriptional regulation across all cell types, especially neurons.

\section{ACKNOWLEDGMENTS}

We thank Laura Schulz and Michael Garcia for comments that improved the manuscript. This work was funded by grants from the NSF (IOS- 0615160) and the Craig H. Neilsen Foundation (83026). 
synaptic activity. J. Biol. Chem. 282, 37783-37793.

Boiko, T., Van Wart, A., Caldwell, J. H., Levinson, S. R., Trimmer, J. S., and Matthews, G. (2003). Functional specialization of the axon initial segment by isoform-specific sodium channel targeting. J. Neurosci. 23, 2306-2313.

Bramham, C. R., and Wells, D. G. (2007). Dendritic mRNA: transport, translation and function. Nat. Rev. Neurosci. 8, 776-789.

Bucher, D., Johnson, C. D., and Marder, E. (2007). Neuronal morphology and neuropil structure in the stomatogastric ganglion of the lobster, Homarus americanus. J. Comp. Neurol. 501, 185-205.

Bucher, D., Prinz, A. A., and Marder, E. (2005). Animal-to-animal variability in motor pattern production in adults and during growth. J. Neurosci. 25, 1611-1619.

Caldwell, J. H., Schaller, K. L., Lasher, R. S., Peles, E., and Levinson, S. R. (2000). Sodium channel Nav1.6 is localized at nodes of Ranvier, dendrites, and synapses. Proc. Natl. Acad. Sci. U.S.A. 97, 5616-5620.

Giuditta, A., Tai Chun, J., Eyman, M., Cefaliello, C., Bruno, A.P., and Crispino, M. (2008). Local gene expression in axons and nerve endings: the glia-neuron unit. Physiol. Rev. 88, 515-555.

Giustetto, M., Hegde, A. N., Si, K., Casadio, A., Inokuchi, K., Pei, W., Kandel, E. R., and Schwartz,J.H. (2003). Axonal transport of eukaryotic translation elongation factor lalpha mRNA couples transcription in the nucleus to long-term facilitation at the synapse. Proc. Natl. Acad. Sci. U.S.A. 100, 13680-13685.

Goldman, J.E.(1983).Immunocytochemical studies of actin localization in the central nervous system. J. Neurosci. 3, 1952-1962.

Golowasch, J., and Marder, E. (1992). Ionic currents of the lateral pyloric neuron of the stomatogastric ganglion of the crab. J. Neurophysiol. 67, 318-331.

Graubard, K., and Hartline, D. K. (1991). Voltage clamp analysis of intact stomatogastric neurons. Brain Res. 557, 241-254.

Hobert, O. (2008). Gene regulation by transcription factors and microRNAs. Science 319, 1785-1786.

Hooper, S. L., O’Neil, M. B., Wagner, R., Ewer, J., Golowasch, J., and Marder, E. (1986). The innervation of the pyloric region of the crab, Cancer borealis: homologous muscles in decapod species are differently innervated.J. Comp. Physiol. A 159, 227-240.

Kilman, V.L., and Marder, E. (1996). Ultrastructure of the stomatogastric ganglion neuropil of the crab, Cancer borealis. J. Comp. Neurol. 374, 362-375.

Martin, K. C., Barad, M., and Kandel, E. R. (2000). Local protein synthesis and its role in synapse-specific plasticity. Curr. Opin. Neurobiol. 10, 587-592.

Maynard,D. M., and Dando, M.R. (1974). The structure of the stomatogastric neuromuscular system in Callinectes sapidus, Homarus americanus and Panulirusargus (Decapoda Crustacea). Philos. Trans. R. Soc. Lond. B Biol. Sci. 268, 161-220.

Michaelevski, I., Segal-Ruder, Y., Rozenbaum, M., Medzihradszky, K. F., Shalem, O., Coppola, G., HornSaban, S., Ben-Yaakov, K., Dagan, S. Y., Rishal, I., Geschwind, D. H., Pilpel, Y., Burlingame, A. L., and Fainzilber, M. (2010). Signaling to transcription networks in the neuronal retrograde injury response. Sci. Signal. 3, ra53.

Rather, P. N., and Moran, C. P. Jr. (1988). Compartment-specific transcription in Bacillus subtilis: identification of the promoter for gdh.J. Bacteriol. 170, 5086-5092.
Satoh, H., Delbridge, L. M., Blatter, L. A., and Bers, D.M. (1996). Surface:volume relationship in cardiac myocytes studied with confocal microscopy and membrane capacitance measurements: species-dependence and developmental effects. Biophys. J. 70, 1494-1504

Schulz, D. J., Goaillard, J. M., and Marder, E. (2006).Variable channel expression in identified single and electrically coupled neurons in different animals. Nat. Neurosci. 9, 356-362.

Schulz,D.J., Goaillard, J.M., and Marder,E. E. (2007). Quantitative expression profiling of identified neurons reveals cellspecific constraints on highly variable levels of gene expression. Proc. Natl. Acad. Sci. U.S.A. 104, 13187-13191.

Smith, D. S., and Pate Skene, J. H. (1997). A Transcription-dependent switch controls competence of adult neurons for distinct modes of axon growth. $J$. Neurosci. 17, 646-658.

Smith, K. E., Gibson, E. S., and Dell'Acqua, M. L. (2006). cAMP-Dependent protein kinase postsynaptic localization regulated by NMDA receptor activation through translocation of an A-kinase anchoring protein scaffold protein. J. Neurosci. 26, 2391-2402.

Spooner, B. S., and Holladay, C. R. (1981). Distribution of tubulin and actin in neurites and growth cones of differentiating nerve cells. Cell Motil. 1, 167-178.

Thuma, J. B., White, W. E., Hobbs, K. H., and Hooper, S. L. (2009). Pyloric neuron morphology in the stomatogastric ganglion of the lobster, Panulirus interruptus. Brain Behav. Evol. 73, 26-42.

Tobin, A. E., Cruz-Bermudez, N.D., Marder, E., and Schulz, D.J. (2009). Correlations in ion channel mRNA in rhythmically active neurons. PLoS One 4, e6742.
Tubing, F., Vendra, G., Mikl, M., Macchi, P., Thomas, S., and Kiebler, M.A. (2010). Dendritically localized transcripts are sorted into distinct ribonucleoprotein particles that display fast directional motility along dendrites of hippocampal neurons. J. Neurosci. 30, 4160-4170.

Weimann, J.M., Meyrand, P., and Marder, E. (1991). Neurons that form multiple pattern generators: identification and multiple activity patterns of gastric/ pyloric neurons in the crab stomatogastric system. J. Neurophysiol. 65, 111-122.

Yuan, A., Mills, R. G., Bamburg, J. R., and Bray, J. J. (1999). Cotransport of glyceraldehyde-3-phosphate dehydrogenase and actin in axons of chicken motoneurons. Cell Mol. Neurobiol. 19, 733-744.

Conflict of Interest Statement: The authors declare that the research was conducted in the absence of any commercial or financial relationships that could be construed as a potential conflict of interest.

Received: 21 July 2010; paper pending published: 30 August 2010; accepted: 09 October 2010; published online: 01 November 2010.

Citation: Ransdell JL, Faust TB and Schulz DJ (2010) Correlated levels of $m R N A$ and soma size in single identified neurons: evidence for compartment-specific regulation of gene expression. Front. Mol. Neurosci. 3:116. doi: 10.3389/fnmol.2010.00116 Copyright $\odot 2010$ Ransdell, Faust and Schulz. This is an open-access article subject to an exclusive license agreement between the authors and the Frontiers Research Foundation, which permits unrestricted use, distribution, and reproduction in any medium, provided the original authors and source are credited. 